\title{
The perception of the Dumagat teachers on the influence of KPJPL to the enrichment of their mother tongue
}

\author{
Ibrahim Sharah \\ Department of Communication, Journalism and Multimedia \\ Arts \\ Lyceum of the Philippines University \\ Manila, Philippines
}

\author{
Venturina Fiella May \\ Department of Communication, Journalism and Multimedia \\ Arts \\ Lyceum of the Philippines University- Manila \\ Manila, Philippines \\ Villareal Ariza Joyce \\ Department of Communication, Journalism and Multimedia \\ Arts \\ Lyceum of the Philippines University- Manila \\ Manila, Philippines
}

\begin{abstract}
Philippines holds such great cultural diversity by having an estimate of 14- 17 million Indigenous Peoples (IPs) belonging to 110 ethno-linguistic groups. However, in the Philippines indigenous people are experiencing deprivation of access to quality education which is a major factor contributing to social marginalization, poverty and dispossession. On the other hand the Lyceum of the Philippines COSel ADHIKA which stands for Arugain ang Dakilang Hiyas ng Kalikasan at Katutubong Karunungan is one of the non-government organizations that struggles to help the Dumagat, which is one of the indigenous people in the Philippines through supporting their educational needs by establishing the Katutubong Paaralan ni Jose P. Laurel (Native school by Jose P. Laurel). One of the main priority of the school is to encourage the usage of the Dumagat's mother tongue. In connection to this, the researchers of this study interviewed the Dumagat teachers and observed the Dumagats in order to identify the importance of language to the Dumagats's culture as well as to analyze the changes and influences made by the integration of JPL elementary school specifically to the language of the Dumagats.
\end{abstract}

Keywords-indigenous people; Dumagat; perception; language; education; teachers; Lyceum of the Philippines University

\section{INTRODUCTION}

Most of the significant characteristics of the Philippines culture were built by different indigenous groups in our country. According to the Climate Change, Cultural Communities, Environment and Natural Resources Chairperson, Loren Legarda "Indigenous people have shaped our story as a Filipino people- our music, arts and dance, our native knowledge and skills, our deeply held beliefs, our creativity, our sustainable ways of living with our physical environment and most important, our self-worth." Aside from their contributions to our culture they also play a vital role in protecting our lands and preserving our virtues [1]. For many years that we are conquered by other countries, they were able to preserve and cultivate our culture.

Notwithstanding of their distinct contributions to the country's social and cultural welfare, many of these indigenous peoples are still excluded from society and deprived of their rights as equal citizens of the country ("Identification of indigenous people" n.d., para. 5). One of these rights is their right for education. In fact indigenous people not only in our country have been experiencing deprivation of access to quality education which is a major factor contributing to social marginalization, poverty and dispossession [2]. Although education is the top priority of the government, not all indigenous groups receives adequate support for education mainly due to the remoteness of their ancestral domains [3].

In the fertile mountain range of Sierra Madre in Quezon Province, inhabited by one of the major groups of indigenous people of Southern Tagalog which are the Dumagats which means "gubat" (forest) and "hubad" (naked) or "taga dagat" (sea gypsies), are known to be nomads or people who don't have permanent homes to stay. As time passed, several of these nomads learned to remain on a certain place. Most of these ethnic tribe can be found in the town of General Nakar while few of them can be spotted in three municipalities of Polilo Island. As the main source of livelihood, the Dumagats depend on farming, kaingin, paid labor, vending logs and other forest commodities. Secondarily, they rely on fishing, hunting animals, gathering crops and other natural bounties for survival [4].

Living in a remote area along the Pacific Coast Line, the Dumagats of General Nakar are one of the tribes that remained untouched by civilization. Because the Dumagats lived in the remote area in General Nakar which is hard to reach by civilized people, they remained isolated for many years and practiced their old ways of living. They have been considered uncivilized for many years and was degraded by the society 
because of lack of education due to poverty and difficulty of reaching schools due to distance. According to an interview of GMA News to one of the Dumagats, he said "It's hard. We only have this forest to roam around. We cannot mingle with other people in the town. They look down on us like we are of no value because we know nothing."

Until 2009 when LPU researchers found 27 Dumagat families in Barangay Anoling, General Nakar which served as their resting place whenever they go to the center towns or visit their children in school in Infanta. Even so, some kinsmen of these families are in their original home located in Sitio Masla under Barangay Sablang. After one year, the LPU team returned to Barangay Anoling wherein they found out that more Dumagats now permanently lived in Masla. They also discovered that the children of the tribe have to walk for 45 minutes just to reach the nearest school in the area of Barangay Sablang. It is in 2011 when the Lyceum of the Philippines University initiated a comprehensive program for IP education through their Community Outreach and Service Learning Center [5]. It was here that they began regular interactions with the Dumagats and decided to put up a community library and a school for their own kind.

On the other hand, in 2011, The Philippines started "indigenizing" its basic education curriculum for the country's various ethnic groups to boost the development of what has been regarded as marginalized people without dissolving their respective cultures and traditions [6]. According to Rozanno Rufino of the Education Department's Indigenous Peoples Education Office "They (indigenous people) are saying that they don't want their culture to be forgotten. They said there is no point in having their kids know how to read and write, and learn about Western literature if they do not know the essence of their own culture." This means that although they wanted to attain education to innovate their way of living, they still wanted to sustain their culture which they protected for many years, that is how important culture is for them [7].

In connection to this in 2015 DepEd adopted the Indigenous Peoples Education Curriculum Framework (DepEd Order No. 32, s. 2015) [8] which guides different schools and other education programs in contextualizing the $\mathrm{K}$ to 12 Curriculum based on their respective educational and social contexts of Indigenous communities. In line with this, DepEd has started a training program for teachers and school heads in schools serving indigenous communities. The Indigenous people Education Curriculum is designed as a culturallyappropriate and responsive curriculum which is based on the defining features of indigenous communities: the ancestral domain, the community's worldview, and its indigenous cultural institutions [8, para. 1-3].

One of the significant part of culture is language. Language is much more than just a means of communication. It is also an inseparable part of our culture [9]. However in the case of the Dumagats, their language is slowly being forgotten because it is no longer being learned by their children. Tagalog, which they use to communicate with their lowland patrons, is inexorably altering their mother language with the incorporation of new words [10].
According to the Indigenous people rights act no 8371, The State shall provide equal access to various cultural opportunities to the ICCs/IPs through the educational system, public or private cultural entities, scholarships, grants and other incentives without prejudice to their right to establish and control their educational systems and institutions by providing education in their own language, in a manner appropriate to their cultural methods of teaching and learning [11]. Therefore educators provided for the Indigenous people should be proficient to their language for them to teach without discouraging the use of the IP's native language.

Therefore the researchers of this study identified the importance of language to the Dumagats's culture and also analyzed the changes and influences made by the integration of JPL elementary school specifically to the language of the Dumagats through the perception of the teachers in the KPJPL.

\section{Statement of THE Problem}

As a part of the Philippine society, the tradition and values of the Dumagats reflect the Philippine culture. Therefore to further understand their culture, the researchers conducted a Qualitative research on the perception of the Dumagat teachers with regards to the influence made by KPJPL to the enrichment of their mother tongue. Moreover, this study aims to answer the following questions: (1) How important is the language to their culture? (2) How do the Dumagat teachers enrich the native language of the Dumagat tribe? and (3) What are the factors that weaken their native tongue?

\section{OBJECTIVES}

The objective of this study is to conduct a study through Indepth interview with the teachers in the community. The objectives are as follows:

- To analyze how the teachers preserve their mother tongue.

- To examine what are the factors that weaken the Dumagat dialect.

- To explain and give deeper meaning on the importance of language in their culture.

- To scrutinize how the KPJPL helped in the enrichment of the Dumagat language.

\section{SCOPE AND LIMITATIONS}

\section{A. Scope}

This study identified the perception of the Dumagat teachers who were currently teaching in Barangay Sablang, Sitio Masla General Nakar Quezon at the Katutubong Paaralan ng Jose P Laurel the influence of KPJPL to the enrichment of their mother tongue. The researchers mainly gathered data through an In-depth interview among the Dumagat teachers which was conducted for one day (March 9 to 10 2017)

\section{B. Limitations}

This study will not cover the influence of education to other aspects of their culture such as religious beliefs, lifestyle and livelihood. 


\section{Methodology}

\section{A. Research Design and tool}

The researchers made use of qualitative research design. Qualitative research begins with assumptions, a worldview, the possible use of theoretical lens, and the study of research problems inquiry into the meaning individuals or groups ascribe to a social or human problem [12][13]. This design involves engagement between the researchers and the participants, resulting to a deeper meaning rather than just explaining numbers.

In the natural setting of the participants (Dumagats) in General Nakar, the researchers utilized the qualitative ethnographic research by exploring and observing the Dumagat culture as well as their community in the point of view of the Dumagat themselves. Ethnography is the study of of social interactions, behaviours, and perceptions that occur within groups, teams, organizations, and communities [14].

\section{B. Research method/tool}

This study used the In Depth Interview as the researchers' tool to help them derive meaningful codes in their study. Indepth interview is a qualitative research technique that involves conducting intensive individual interviews with a small number of respondents to explore their perspectives on a particular idea, program, or situation (Boyce, 2006).

\section{Participants}

The study's participants are the native teachers or community volunteers who had been teaching the mother tongue and culture development to the tribes of Dumagats in Sitio Masla, General Nakar in Quezon Province.

\section{Data gathering procedure}

For the procedure of data gathering, the researchers used In-depth interview. The researchers interviewed the teachers all at once. The discussion started by asking the participants general questions such as personal information about them and their occupation and brief discussion of what will be the content of the interview. The researchers used phone recorders and DSLR camera to cover the interview.

\section{RESULTS AND ANALYSIS}

KPJPL promotes teaching of the mother tongue among the Dumagat youth to preserve their culture

"The main emphasis of teaching in KPJPL is the preservation of language as an important component of their culture"

Language is essential in the preservation of culture. In connection to this, language is one of the factors that makes up our culture, it serves as a verbal way of expressing our culture. Among all the factors that makes up culture such as religion, cuisine, social habits, music and arts, language is the one which has a deeply rooted relationship to culture. As stated in SaphirWhorf hypothesis, language is used to maintain and convey culture and cultural ties. Different ideas stem from differing language use within one's culture. Therefore, through preserving language a group of person could also preserve their culture. Moreover, the Dumagats in the community of Sitio Masla feels that they could expressed their feelings better when they are speaking the native dialect. They consider the Dumaget language as a representation of their culture and way of living.

\section{Discrimination is the primary cause why the Dumagat dialect was disremembered.}

"Dumagats unlearned their native dialect because of shame due to discrimination.”

In the Philippines since the Dumagats are natives they are not exempted from any form of racial discrimination and bullying. In school, the Dumagats received discrimination primarily from the Tagalogs. Moreover, discrimination has been a big dilemma not only for the Dumagats but also to all the ethnic groups in the Philippines. Among the rural sectors, the Indigenous Peoples remained to be the most marginalized, socio-economically deprived, discriminated and neglected. High illiteracy rate remains the big social problems among the IPs.

\section{Tagalog language helps in understanding the "Dumaget" dialect.}

"To better understand the Dumagat language, the teachers integrated Tagalog language in their teaching”

Since majority of the Dumagat youth nowadays used the Tagalog as their primary language, the teacher is having a hard time to talk to them and to teach them straight Dumagat language. Therefore, the Dumagat teachers made used of both Tagalog and Dumagat dialect and integrate it in their way of teaching to help the children understand the lessons. The teachers would translate the Dumagat words to Tagalog to gain interest from the children and to make it easier for them to understand their native tongue.

\section{KPJPL serves as the initial advocate of learning the Dumaget language.}

"KPJPL encourages the Dumagat youth to learn the "Dumaget” language"

When LPU arrived in Sitio Masla, they encouraged the whole Dumagat community to learn and to revive the use of their native tongue. They explained to them and made them understand the importance of having and practicing one's native dialect. Moreover, KPJPL was built to help the children attain their goals through education and to enrich their use of their mother tongue. LPU put a lot of attention to the children, since they were the ones who are not literate of their native tongue and they will be the next generation of Dumagat elders that would pass over their culture to the future generations.

\section{Dumaget language can be taught in various ways.}

"In teaching the Dumagat language the teachers in the community applied/used different teaching methods"

Aside from speaking and writing, there are other various ways that the teachers made use in teaching the Dumagat children such as presenting to them the actual representation of 
a certain object which pertains to the native word. This type of method is considered as the most effective way of teaching for the community volunteer teachers. Moreover, the teachers also play native songs that will help the children understand their mother tongue better. Furthermore, the teachers do more researches about their mother tongue and culture with the help of the elders in the community.

\section{The integration of KPJPL makes education accessible to} the Dumagat community.

"Learning becomes accessible for the community when the KPJPL was integrated"

Considering the fact that the Dumagats are living in a remote area, the situation makes it hard for the government to provide their need for education. Until in 2011 Lyceum of the Philippines COSel ADHIKA (Arugain and Dakilang Hiyas ng Kalikasan at Katutubong Karunungan) came to the area and establish the Katutubong Paaralan ng Jose P Laurel as a part of their comprehensive program for IP education through their Community Outreach and Service Learning Center. In the past the children of the tribe have to walk for 45 minutes just to reach the nearest school in the area of Barangay Sablang. This situation changed through the efforts of the COSel department which envisions to make the Jose P Laurel's legacy a tool in helping the Dumagat tribe in General Nakar to attain education and be exposed to modernization and innovation.

\section{LPU helps in improving the teaching skills of the teachers in the community.}

"LPU helps the teachers to improve their teaching of the native dialect”

Since 2011 when LPU integrated KPJPL in the Dumagat community, they did researchers regarding the concerns of the community as a whole especially in education. Before, the teachers just use practical way of teaching wherein they only teach basic things through their surroundings without any definite lesson plans. That is why LPU conducted seminars and trainings to volunteer Dumagat teachers to help them teach the Dumagat children more effectively.

\section{Socialization among the community helps in the process of learning the native dialect}

"Interaction helps in the process of learning the language"

Interaction is one way of learning a certain language by improving fluency. As stated in Long's Interaction Hypothesis when we speak or write to a native speaker, or even with a nonnative speaker, we negotiate meaning, and it is precisely because of this negotiation that the process of learning is facilitated. The adjustments we make during a conversation, as well as the provision of negative evidence by our interlocutor (through corrections and feedback), all contribute to this process. In short, conversation or simple chatting gives us a lot of opportunities for producing modified output. Furthermore, when we make a mistake and our interlocutor corrects it, we are likely to remember it and not making it again. This is because we pay attention to it and we notice it.
Dumagat language is not the same with the Tagalog dialect.

"Dumaget is different in many aspects compared to the Tagalog dialect.”

The researchers have noticed that most of the non-Dumagat people have the common stereotype that Dumaget dialect is just a deeper version of Tagalog. However by the means of indepth interview with the teachers in the KPJPL who teach the native tongue, the researchers were able to verify that Dumaget dialect differs to the Tagalog language in different aspects such as; where to put stress in each word, spelling and the actual words used in certain things, such as "Pumarito" (Come over) in Tagalog which is "dumio" in Dumagat. Moreover, the stereotype that the two language are the same started when the Dumagat's started speaks using both languages (mixing Dumaget and Tagalog).

\section{CONCLUSIONS AND RECOMMENDATIONS}

This chapter includes the summary of findings from the Indepth interview conducted by the researchers on the perception of the teachers in the Sitio Masla on the influence of KPJPL to the enrichment of their mother tongue. It aimed to determine what are the major results, conclusions, and recommendations offered by the researchers.

\section{A. Conclusions}

From the data analyzed and interpreted, the researchers arrived with the following conclusions:

The integration of KPJPL has a big influence in the preservation of their language, through enlightening the community about the role of their native dialect to their identity as well as in building a better future for them. Dumagat dialect which is called "Dumaget" was disremembered by the Dumagats in Sitio Masla because of the discrimination they received from the low landers, primarily the Tagalogs. Dumagats have been stereotyped as illiterate because of the way they speak that is why they stopped using their native dialect until only few of them are capable of speaking it. Since the Dumagat youth are more fluent in speaking Tagalog, for them to thoroughly comprehend the Dumagat words taught in the school, the teachers must translate it first into Tagalog language. When the KPJPL was established, the Dumagats started to perceive their native dialect not only as an essential part of their culture, but also as a key for them to have a better future. In teaching the Dumagat language, the teachers use various methods so that the students could better learn and understand the mother tongue. Aside from writing and speaking, the teachers also prefer to use actual representation of words such as fruits and allow the students to taste it. Accessibility of education becomes easier when the KPJPL was integrated in the community, it provided adequate educational needs among the youth. Moreover, the school encourages the youth to give great importance to education and to enrich their mother tongue.

Socialization also helps in learning the language that is why the teachers encourages the students to use Dumaget in their daily conversations. This perception is supported by Long's Interaction Hypothesis, wherein it stated that when we speak or 
write to a native speaker, or even with a nonnative speaker, we negotiate meaning, and it is precisely because of this negotiation that the process of learning is facilitated. Therefore, through interaction the Dumagats tend to have a process of validation through negotiating whether they are speaking the dialect correctly or not. Generally, KPJPL has a positive influence in the enrichment of the Dumagat language through prioritizing the learning of the mother tongue in the educational system of the school. Moreover, the KPJPL encourages the youth to learn their native tongue through introducing them that language is an essential part of their culture and identity. Furthermore, the KPJPL helps them overcome discrimination, and helps them to be proud of their mother tongue.

\section{B. Recommendations}

Based on the results of the study, the researchers suggest the following recommendations:

- The researchers, endorse this study to be a reference for future researches in the same field

- For the future researchers, it is recommended to conduct studies that will determine the other factors (aside from discrimination) why the Dumagats dialect was disremembered. This is to better understand the cause of the problem and to be able to formulate an effective solution.

- For future researchers that will have the same field of study a longer time of immersion to the community is suggested to have a comprehensive observation on their way of learning and teaching the mother tongue so that a stronger data would be generated.

- Policies that the government implements when it comes to the rights of the IPs must be improved and strictly imposed.

- KPJPL must provide seminars and teaching guides that are in Tagalog language as requested by the teachers, so that they could be able to fully comprehend the content. This will help them improve their skills in teaching the mother tongue

For the Department of Education, they must give aid to the KPJPL in helping the Dumagat youth and teachers through providing additional support (incentives for the teachers, facilities, et cetera) to the community. Moreover, the DEPED should re-establish their existing programs for IPs to a much better and effective one.

\section{REFERENCES}

[1] L. Legarda, "Charting Our Resilient Future: The Biodiversity and Ecosystem Approaches a Multi-stakeholder Forum," Senate of the Philippines 17th congress, March 13, 2017. [Online]. Available: https://senate.gov.ph/press_release/2017/0313_legarda1.asp.

[2] United Nations Human Rights Office of the Higher Commissions, “Quality Education for Indigenous Peoples,” October 22, 2009. [Online]. Available: http://www.ohchr.org/EN/NewsEvents/Pages/QualityEducationForIndig enous Peoples.aspx.

[3] TEBTEBBA, "Situation of Indigenous Peoples in the Philippines: Submission to the 59th Session of CESCR," Indigenous People International Centre for Policy Research and Education, 2016. [Online]. Available: $\quad$ http://tebtebba.org/index.php/content/383-situation-ofindigenous-peoples-in-the-philippines-submission-to-the-59th-sessionof-cescr.

[4] Escamillas, "Let’s Get to know the Dumagat Tribe,” 2012. [Online] Available:

http://www.wowquezon.com/features/people/let\%E2\%80\%99s-get-toknow-the-dumagat-tribe/.

[5] L. Bolido, “Education brings hope to Dumagat of Quezon,” Inquirer.net, 2015. [Online]. Available: http://newsinfo.inquirer.net/710137/education-brings-hope-to-dumagatof-quezon.

[6] R. Calunsod "Philippines 'indigenizes' basic education," ABS-CBN NEWS, October 25, 2013. [Online]. Available: http://news.abscbn.com/nation/10/25/13/philippines-indigenizes-basic-education.

[7] R. Rufino, ”Philippines 'indigenizes' basic education,” ABS-CBN NEWS. October 25, 2013. [Online]. Available: http://news.abscbn.com/nation/10/25/13/philippines-indigenizes-basic-education.

[8] Department of Education, "DepEd issues IPEd Curriculum Framework," August 11, 2015. [Online]. Available: http://www.deped.gov.ph/pressreleases/deped-issues-iped-curriculum-framework.

[9] N. Brophy "Reasons Language is Important to Any Culture [R. Scudder, Eds.].” Bright Hub Education, September 11, 2012. [Online]. Available: http://www.brighthubeducation.com/language-learning-tips/99894-whylanguage-is-important-to-culture/.

[10] J. T. Peralta, “Casiguran Agta / Casiguran Dumaga,” Aurora Philippines, 2000-2017. [Online]. Available: http://www.aurora.ph/baler-aurorabook/agta-dumagat.html.

[11] Government of the Philippines, Republic Act No. 8371, Official Gazette, October 29, $1997 . \quad$ [Online]. Available: http://www.gov.ph/1997/10/29/republic-act-no-8371/.

[12] J. Creswell, “Qualitative Inquiry and Research Design,” 2007. [Online]. Available: http://courses.coe.uh.edu/lgauna/readings/Creswell.pdf.

[13] "Qualitative Field Research", n.d. [Online]. Available: http://www.oxfordjournals.org/our_journals/tropej/online/ce_ch14.pdf.

[14] [22] S. Reeves, "Qualitative research methodologies: ethnography," 2008. [Online]. Available: Retrieved http://www.bmj.com/content/337/bmj.a1020. 